keeping cats, but there is not, as far as I can find out; any religlous objection. As soon as they realize the advantage of keeplng cats they willingly agree. The Bhowanl Dhers, who are not a numerous people, object to keeping cats because the death of a cat in their house puts them out of caste, and they have to break all their earthen vessels and perhaps entertain their caste fellows. The birth of sittens in their house is also a serious matter, but to avold this latter misfortune, those who have recognized the value of keeping cats now keep male cats. These people sometimes suffer severely from plague, for example, in Dhaba vlliage the Bhowanl group of houses suffered from plague while the group of houses occupled by the Tells, where the percentage of cats was over fifty, escaped.

\title{
RAT.PROOF HOUSES.
}

Dr, Ashburton Thompson is a strong advocate of the rat-proof house, and theoretically this idea is excellent. Bat most houses in an Indlan village are bullt of mud, and in all probability will be bullt of mud for centuries to come. The mud wall might be called the black rat's home, for it is in the mud wall that it likes to make its burrow and nest. The Bhowanl Dher in thls district often lives In a wattle hut, and those who live in such huts are remarkably free from plague, because there is little attraction for the rat.

\section{Inocunation versus Cats.}

While we did not know how plague was spread, there was a great deal to be said in favour of Inesulation; bat now that we know that plague is spread by rats and that without rats there will be no epidemic, surely it is much better to try and remove rats ; and when we know that rats can be kept away by cats there can be little question that the best way to prevent plague is to keep cats. In this district, where vaccination is an exceedingly popular measure and where the elder men conld soon convince the doubter who has perhaps never seen a case of small-pox of the value of vacclnatlon, the people have not readily taken to inoculation, and their reasons might be stated somewhat like thls :

\section{Inoculation.}

Efficlent for a few months. Does not strike at the root. Very expensive.

Large establishment required. No establishment required.

Necessary to Inoculate every One cat protects a household.

member of household.

Not an absolute preventive.

When the number is sufficient all risk of plague is abolished.

Sore arme, ferer, and absence No Inconvenlence.

from work.
Many objections on the part of Extraordinary willingness.

the people.

Not favoured by tradition or Strong tradition in favour of rellgion. keeplng cats (Parsis and Bhowani Dhers excepted).

Concrosion.

In the early days of plague epidemics many mistakes were made. Oordons were drawn round villages and towns so that Infected people could not get in, but infected rats might steal in unobserved. Disinfection was practised with great vlgour, but while this operation was in progress the rat was sitting comfortably in its burrow, ready to come ont as soon as the disinfection operations were over. The plague patlent was hastily segregated to a plague camp, but we now know that plague (bubonic) Is practically never conveyed direct from man to man, 80 that it has come to be a common saying that "the safest place in a plague epldemic is a plague camp," and those of us who have had charge of plague camps know that those gervants who lived in the camp practically never took plague, although they were handling plague patients all day. A few cases of plague have been occurring daily in this distrlct for some time, and from dally inguirles which are being made I think there is good reason to believe that the duration of plague in India depends on the time it will take belore it is generally recognized that the cat is the best plague preventer. At any rate, I hope I have shown that there are reasonable grounds for making further inquiries on the lines suggested here.

\section{RFFERENCE}

1 Indian Medical Gazette, October, 1907
SPORADIC KALA-AZAR IN CALCUTTA, WITH NOTES OF A CASE TREATED WITH A'TOXYL.

By U. N. BRAHMAOHARI, M.A., M.D.,

TEACHER OF MEDICINE AT THE CAMPBELL MEDICAL SCHCOL, CALCUTTA.

KALA.AZAR, as used in this article, may be defined as the disease caused by the Lelshman-Donovan bodies. Its epldemlc manlfestation, which is seen in Assam, more irequently goes by thls name. It is endemic round about Calcutta and probably occurs in the clty Itself.

Last year I examined the spleen blood of nearly 150 cases of enlarged spleen admitted into my wards in the Campbell Hospital, and lound the parasite of kala-azar in 60 cases. From this it is seen that cases of thls disease are Irequently admitted Into the Calcutta hospltals.

No two cases came from the same house, and I have not succeeded in corroborating the fact that the disease is limited to individusl houses or families; 91.7 per cent. of my cases were Hindus, while 8.3 were Mohammedans, giving a proportion of nearly 11 to 1 . Out of the total number of patients admitted into my wards in 1907, about 75 per cent. were Hindus and 17.5 per cent. Mohammedans, giving a proportion of nearly 4 to 1 . It will thus be seen that Hindus are more Irequently affected by the disease than the Mohammedans, and if this fact is corroborated by more extended observations it may probably throw some light on the etiology of the disease; 33 per cent. of my cases were below the age of 20. I have not met with any case above the age of 55. The cases came to my wards during all the parts of the jear, the largest number of admissions belng during the period of April to Angust, but especially in the month of May.

It was difficult to trace from the history of the cases where the disease was contracted. Most of them pointed, however, to the disease having been contracted in the nelghbourhood of Calcutta, and a few seemed to have contracted the disease In the clty Itself, as they never went out of $1 \mathrm{t}$. None of my cases came from the epidemic area of Assam. Some came from Orlssa, Eastern Bengal, district of Murshidabad and Behar.

Most of my cases were chronic, with history of lllness for several months, and with the spleen extending $3 \mathrm{ln}$. or more below the costal arch. In a large majority the liver was aleo moderately enlarged, while in a very few cases the liver was very much more enlarged than the spleen, which extended just an inch or so below the ribs. I have not met with a case in whlch the spleen was not at all enlarged.

As regards the early symptoms of the disease, knowledge is atlll verg limited. The patients met with in the hospltal wards have suffered for a long time. I give here a summary of the early symptoms of the disease as gathered from the patlents.

In one class of cases we get a history of Intermittent attacks of fever, quotidian for some time, and later on becoming irregular with or without rigors, lasting for several months and not benefited or only temporarily benefited by quinine. In a second class there is a hlatory of a few previous attacks of lever, continulng for some time on each occasion, the spleen becoming slowly and steadily enlarged. In a third class there is a history of attacks of low fever, continued for several months, with a progressive enlargement of the spleen not benefited by any treatment. In a fourth class there is a hlstory of one or two attacks of remittent fever more or less resembling typhold. In a fifth class the patient gives a history of gastro-Intestinal troubles, with dysenteric or diarrhoelc attacks followed by oedema of the lower extremitles, and attended from time to tlme with ague-like attacks of fever. In all these cases the patient invariably says that there was very slight or no benefit from quinine. Posslbly a large majority of cases begin with attacks of remittent fever.

Among the other symptoms I have observed may be mentloned progressive emaclation, with anaemla, cachexia, oedems of the extremities, diarrhoea, dysentery, whlch may sometimes be very obstinate, and haemorrhages from various parts of the body, such as the skin and mucous membranes.

Oedems of the extremities is sometimes an early symptom; on the other hand, it may be absent even up 
to the last. It Is not easy to explain the cause of this oedema. It appears that we can distinguish two classes of cases-one in which oedema is a marked symptom and the other in which it is not. These two types are well shown in the two accompanying photographs.

I have elsewhere described in detail the varlous types of pyrexla that I rave observed in this disease. ${ }^{1}$ Besides

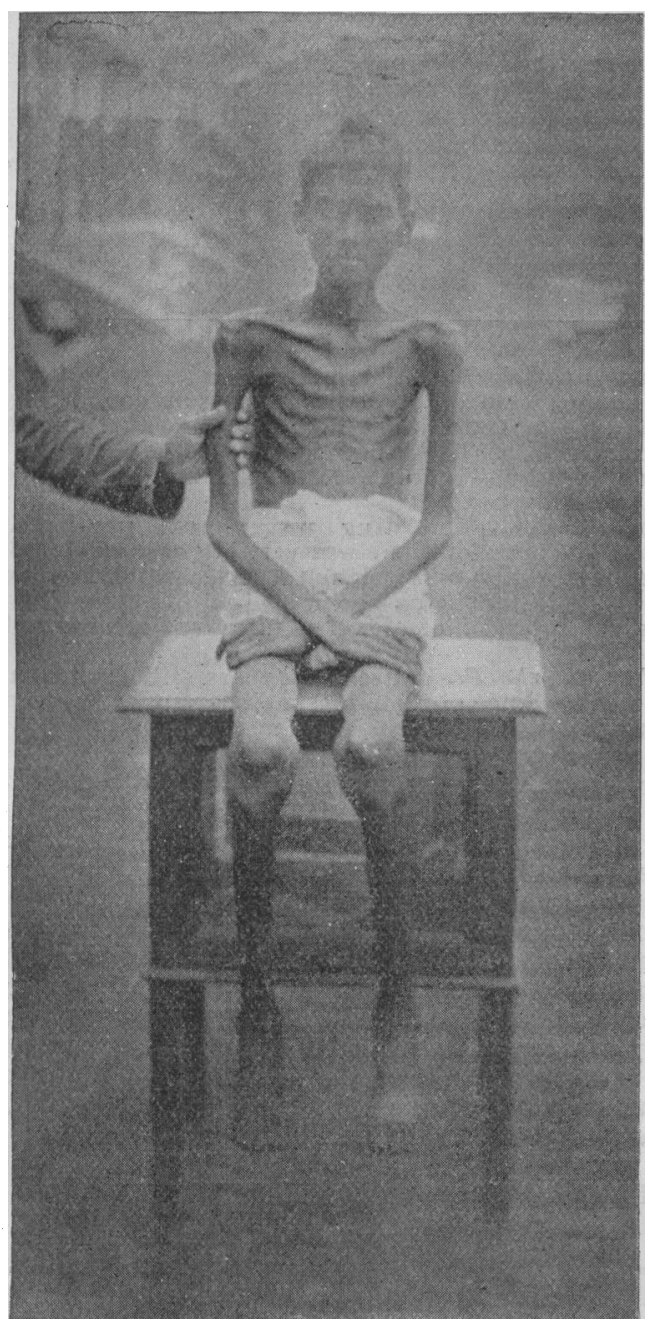

Fig. 1.-Advanced case of kala-azar with no oedema.

these, there may sometlmes be pyrexis of the pyaemic type, there belng more than two remisslons or intermissions in twenty-four hours. Rarely the disease takes on an apyretic coures for an indefinite length of time.

\section{Blood Count.}

In the main my observations corroborate those of Major Rogers. ${ }^{2}$ Leukopenis is extreme, and In many cases the proportlon of white to red is less than ${ }_{10}^{1}$ (Table I).

TabLe $\mathbf{I}$.

\begin{tabular}{|c|c|c|c|}
\hline & Red Corpuscles. & White Corpuscles. & Proportion. \\
\hline 1 & $2,390,000$ & $1,7 \succsim 0$ & $\frac{1}{3 \frac{1}{5} 9}$ \\
\hline 2 & $2.530,0<0$ & 2530 & 10 \\
\hline 3 & $2,740,000$ & 1,792 & $x=5$ \\
\hline 4 & 3,440000 & 2,386 & r⿲彳⿱一土㇒ \\
\hline 5 & $3,170.000$ & $2,38)$ & $13^{1} 35$ \\
\hline 6 & $2,660,000$ & $1,1 \in 0$ & $52 \frac{1}{5} 3$ \\
\hline 7 & $2,763,0<0$ & 1,527 & Iริ $\frac{1}{2}$ \\
\hline 8 & $2,9 \geq 0,000$ & 1,320 & รू้ा \\
\hline 9 & $2,120,000$ & 1.736 & $x^{\frac{1}{2}} \frac{1}{2}$ \\
\hline 10 & $2,3 \geq 0,000$ & 1,600 & ${ }_{17}^{1} 66$ \\
\hline
\end{tabular}

In a number-of cases, though there was a marked leakopenia, yet the proportion of white to red was higher

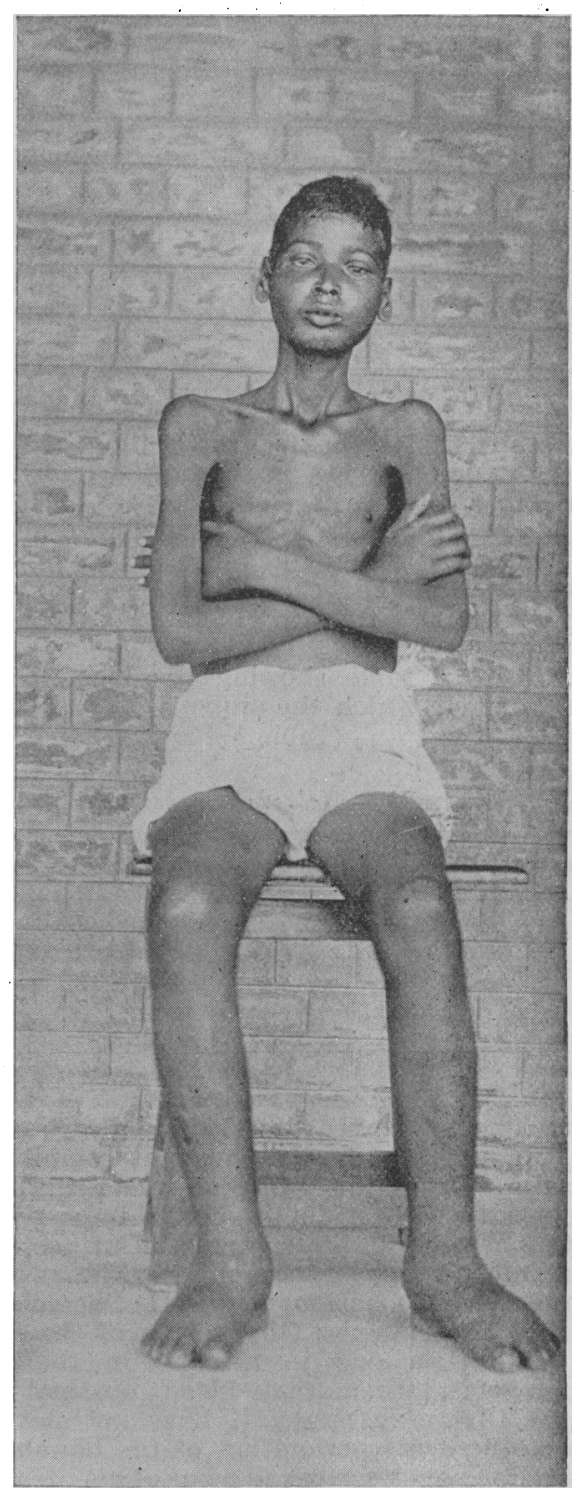

Tig. 2.-Advanced case of kala-azar with marked oedema

than ${ }_{\overline{1} 0^{1} \delta \overline{0}}$. These are probably very advanced cases with extreme anaemla (Table II).

TABLE II.

\begin{tabular}{c|c|c|c}
\hline & Red Corpuscles. & White Corpuscle: & Proportion. \\
\hline 1 & $1,400,000$ & 2,170 & 2,250 \\
2 & 860,000 & 3,870 & $3 \frac{1}{3}$ \\
3 & $1,4 \varepsilon 0,090$ & 3,300 & $3 \frac{1}{2}$ \\
4 & $1,300,000$ & $3 \frac{1}{3}$ \\
\hline
\end{tabular}

In many cases complications often lead to increase in the leucocy te count (Table III).

TABLF IIT.

\begin{tabular}{|c|c|c|c|c|}
\hline & $\underset{\text { Corpuscles. }}{\text { Red }}$ & $\begin{array}{l}\text { White } \\
\text { Cor puscles. }\end{array}$ & Proportion. & Complication. \\
\hline 1 & $2, \S 80,0 \subset 0$ & 7.662 & $3 \frac{1}{4} \pi$ & Pneumonia. \\
\hline 2 & 893,100 & $2,7 \in 8$ & $8 \frac{1}{3}$ & Cancrum oris. \\
\hline 3 & $3,070,000$ & 3,500 & $5 \frac{1}{4}$ & $\begin{array}{l}21 \text { hours atter } \\
\text { application of a } \\
\text { large blister } \\
\text { over the } \\
\text { splente region. }\end{array}$ \\
\hline
\end{tabular}


Lastly; cases that have been recovering or have recovered from cancrum orls, or have been treated with atoxpl for some timo, mas give a higher relative leucocste count than $\frac{1}{1000}$ (Table IV).

TABI.K IV.

\begin{tabular}{|c|c|c|c|}
\hline & Red Corpuscles. & White Corpuscles. & Psoport'on. \\
\hline 1 & $2,340,000$ & ه,569 & ${ }_{s}^{1} \frac{1}{2}$ (Recovery from \\
\hline 2 & 2,600000 & 3,340 & $=\frac{1}{8} \begin{array}{c}\text { caocrumorist } \\
\text { (Treatment }\end{array}$ \\
\hline 3 & $3,4: 0,000$ & 0 & $s \frac{1}{25} \begin{array}{c}\text { (Treatment } \\
\text { with atoxyl) }\end{array}$ \\
\hline
\end{tabular}

Comparing the leucocy te count in kala-azar with what we observe in malarial cachexla, exactly the same concla. sion as that of Major Rogers is reached-namely, that a ratio of red to white corpuscles below It diagnostlc of kala-azar; but, as we have shown above, we may meet with cases without any apparent compllcation, or some with well-marked complications, or others that have taken a favourable turn, in which the proportion may be higher than ioloo.

I append here a table showing the blood count in malarial cacheria, in which the proportion of white to red

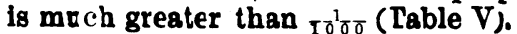

TABLE V.-Malarial Cachexia.

\begin{tabular}{c|c|c|c}
\hline & Red Corpuscies. & White Corpuscles. & Proportion. \\
\hline 1 & $3,240,00$ & 8,060 & 5 \\
2 & $2,238,0 c 0$ & 3,372 & $\frac{3}{165}$ \\
3 & $2,384,(c 0$ & 4,863 & $\frac{1}{65}$ \\
\hline
\end{tabular}

Complioations.

(1) Pneumonla; (2) phthlsls; (3) dyeentery; (4) dlarrhoea ; (5) cancrum oris and its attendant complicatlons (6) haemorrhage from the gums or under the gkin in advanced cases; (7) delirium or coma, in some cafes, shortly before death; (8) albumen In the urine in a few cases, which might ke due to concomitant kidney diseast; (9) paraphimosis: (10) haemontysls; (11) haematemesle ; (12) melaens; (13) epistaxls; (14) oedems of the extrem! tles; (15) splenalgis due to infarcts in the spleen (16) haemorrholds, which may bleed obstinately and profusely; (17) large abscesses. I have not met with a cage in which there was perforation of the bowels, which Captain Christophers descrlbes in some ol his cases.

\section{Prognosis.}

According to $m \nabla$ observations, the prognosis is always grave. I have not the record of a single case which I could pronounce cured; 40 per cent. of my cases died in the hospltal, the most irequent cause of death being intraclable diarrhoea or dysentery.

Treaturant.

So far as mp observatlons go. no drug can kll the parasites. I have used the following drags without success : (1) Qulnine Internally; (2) quinine nypoderml cally; (3) flaorldes; (4) arsenic and some of its new preparations, such as sodil cacodylas, arrhensl, and atoryl; in some cases arrhenal and sodil cacodylas weie given hypodermically; (5) methylene blue internally; (6) methplene blue hypojermically; (7) izal in Increasing doses ; (8) cgllln in increasing doses up to half a drachm thrice a day.

Encouraged by the results of the use of atoxyl in trgp znosomlasis, I gave it an extenslve trial in a few cases, one of wolch has been under my observation for nearly elght months and under atoxgl treatment for nearly slx months. As far ag I am aware, there are no records of a single case in which atoxpl was used for such a prolonged perlod in ka's-8zar.

The patient, aged 30 , a Hindu, had slight oedema of the 1)wer extremities ot the time of admisslon, the spleen extending 8 in. from the left nipple in the middle line.

The effeots of the treatment were as follows :

\section{Body Weight.}

$\begin{array}{llllllll}\text { May } 25,1907 & \ldots & \ldots & \ldots & \ldots & \ldots & 8 & 0 \\ \text { August } 12,1907 & \ldots & \ldots & \ldots & \ldots & \ldots & 7 & 4 \\ \text { September } 9,1507 & \ldots & \ldots & \ldots & \ldots & 7 & \xi_{\frac{1}{2}} \\ \text { November 16, 1907 } & \ldots & \ldots & \ldots & \ldots & 8 & 0 \\ \text { December 29, } 1907 & \ldots & \ldots & \ldots & \ldots & 8 & \xi_{\frac{1}{2}}\end{array}$

2 Rlood-rount.

\begin{tabular}{|c|c|c|c|}
\hline Late. & Red Corpuscles. & Wh:te Cos pusc!es & Proportion. \\
\hline May 2, $1907 \ldots \quad$.. & 2,760 OCO & 1,687 & $x \frac{1}{8} \pi 7$ \\
\hline August 16, $1807 \quad$.. & 2500,000 & 1,600 & $15^{\frac{1}{6} 8}$ \\
\hline September $7,1501 .$. & $2,280,0: 0$ & 1,950 & $11 \frac{1}{17}$ \\
\hline November 18,1907 . & $2 \in 00,(\mathrm{CO}$ & 3,240 & $7 \sqrt{8}$ \\
\hline January $7,1 \leq 08 \quad$.. & $34 i c, 0 c 0$ & 6,500 & $6 \frac{1}{20}$ \\
\hline
\end{tabular}

\section{Pyrexia.}

4. General Condition. - The patlent looks much better in health; the oedema of the extremities has completely disappeared. He is fatter than before, is less ansemic, has no cachexia, and bas got better appetite.

5. Toxic Action.-There were never any symptoms of sreenio polsoning.

6. Local Action.-The drug was almost non-Irrltating. Except on one occasion there was very ellght local irritation on this occasion there was a slough formed which I think was on this occasion there was a slough formed, which I hink was due to the solntion being too hot. In other cases in which
I have given injection of atoxyl no untoward local symptoms

I have glven in
were met with.

7. Effect on the Parasites. -They are still found in the splento blood. Some of them present a granular appearance, but they are still to be seen in large numbere.

8 Spleen. - Not much diminlshed in size.

Before concluding, I would just mention one point, that spleen puncture, though it has been pronounced dangerous by the hlgbest authorities, has never led to any single accldent in any of my cases. I have found that a large hypodermic needle is sufficlent to enable one to draw one or two drops of blood, whlch are almost always sufficient to show the parasltes if they are present. I would therefore recommend that not more than one or two dross of blood should be drawn from the spleen for ordinary diagnostic purposes. It appears to me that the danger of spleen puncture may be reduced to a minimum If one uses a hypodermic needle, gives the patient calclum chloride before and after puncture, enjolns absolute rest In bed, and pats pressure upon the punctured spot for about fifteen minutes after the operation.

Conclusions.

1. Sporadic kala azar is frequently seen in Calcutta hospitals, and is probably endemlc in Calcutta itself. Hindus are probably more affected than Mohammedans.

2. The leucocyte count is of great diagnostic help, but not absolutely so in kala-azar.

3. Atoxgl is borne in very large doses (gr. xv, in one injection) by kala azar patients. It is perfectly harmless and non irritating. Its effect on the parasites is perhaps very slight. While improving the patient's health, it does not remove the cause, though it has apparently some effect upon the pyrexla. In order that it may do any good it must be given in very large doses (gr. xv) as injection every seven or ten days, continued for several months.

4. Spleen Puncture. - It is practically safe if one uses a hypudermic needle and does not draw more than one or two drops of blood.

1 Indian Medical Gazette, January, 1906. " Lancet, March 2nd, 1907.

A COMMITTEe on the use of lead in the manufacture of earthenware and china has been appointed by the Home Secretary. The committee is to consider the dangers attendant on the ure of lead in pottery, and to report how far these can be obviated by improved appliances and methods in lead prccesses, by the limitation of the use of lead, by the substitution of harmless compounds for raw lead, or of other materials for lead, and by other means. The committee is also instructed to consider the danger and injury to health arising from dust or other causes in the manufacture of pottery, and the special rules regulating the decoration of earthenware and chlna The members are: Mr. E. F. G. Hatch (chairman), Mr. A. Vernon Harcourt, F.R.S., Dr. George Reid, Mr. William Burton, and Mr. Bernard Mcore. 